\title{
Heart rate variability: Response to graded head up tilt in healthy men
}

\author{
Sharma $\mathbf{P}^{1}$, Paudel $\mathrm{BH}^{2}$, Singh $\mathrm{PN}^{3}$, Limbu $\mathbf{P}^{4}$ \\ ${ }^{1}$ Lecturer, Department of Physiology, Kathmandu Medical College, Kathmandu, Nepal, ${ }^{2}$ Additional Professor, ${ }^{3}$ Professor, \\ ${ }^{4}$ PG student, Department of Physiology, BP Koirala Institute of Health Sciences, Dharan, Nepal
}

\begin{abstract}
Background: Heart rate variability is actually a misnomer for R to R variability in cardiac cycle. Variation in successive cycle length is called the heart rate variability (HRV). Head-up tilt is a model of studying cardiovascular haemodynamics, which reflects in heart rate variability (HRV).

Objectives: To study the effect of $10^{\circ}$ and $70^{\circ}$ head-up tilt on HRV.

Materials and methods: The study was done in the Department of Physiology using graded head up tilt (passive orthostatism). HRV measurement was done at $10^{\circ}$ and $70^{\circ}$ tilt and compared with supine using standardised methods on 30 consenting healthy males (age $25.37 \pm 3.89$ years). The HRV variables across postures were compared by ANOVA and Bonferroni test.

Results: The heart rate increased at $70^{\circ}$ compared to $10^{\circ}$ and supine $(70.48 \pm 8.17 \mathrm{Vs} 70.22 \pm 8.67$ and $88.51 \pm 12.84 \mathrm{bpm}$, $\mathrm{p}<0.001)$. The $70^{\circ}$ tilt decreased vagal HRV indicators compared to $10^{\circ}$ and supine: SDNN (31.13 $\pm 8.12 \mathrm{Vs} 38.07 \pm 11.29$ and $38.13 \pm 10.89 \mathrm{~ms}, \mathrm{p}<0.05)$, RMSSD (20.06 $\pm 8.47 \mathrm{Vs} 34.23 \pm 14.22$ and $36.16 \pm 12.22 \mathrm{~ms}, \mathrm{p}<0.001)$, NN50 count $(13.03 \pm 20.58 \mathrm{Vs} 45.07 \pm 44.44$ and $55.27 \pm 44.10, \mathrm{p}<0.01)$, pNN50 (3.28 $\pm 6.08 \mathrm{Vs} 14.06 \pm 15.65$ and $16.65 \pm 14.23, \mathrm{p}<0.01)$, HF power $(197.20 \pm 143.76 \mathrm{Vs} 218.17 \pm 155.85$ and $216.87 \pm 150.98 \mathrm{~Hz}, \mathrm{p}<0.05)$, HFnu unit $(24.28 \pm 14.16 \mathrm{Vs} 45.48 \pm 16.34$ and $47.67 \pm 19.89, \mathrm{p}<0.001)$.

The $70^{\circ}$ tilt increased LF power\% (197.20 \pm 143.76 Vs $218.17 \pm 155.85$ and $\left.216.87 \pm 150.98, p<0.001\right)$. LFnu unit $(75.72 \pm 14.76$ Vs $54.52 \pm 16.34$ and $52.32 \pm 19.89, \mathrm{p}<0.001)$, LF: HF $(4.96 \pm 4.08$ Vs $1.53 \pm 1.138$ and $1.69 \pm 1.67, \mathrm{p}<0.001)$ compared to $10^{\circ}$ and supine.

Conclusion: At $70^{\circ}$ tilt, HRV measures, reflecting vagal contribution to cardiac-cycle length, decreased with reciprocal increase in sympathetic activity compared to $10^{\circ}$ or supine leading to increase in sympathetic predominance. A $10^{\circ}$ tilt, which is almost equivalent to lying down with pillow, did not change HRV from supine.
\end{abstract}

Key words: Cardiac cycle, cardiovascular haemodynamics, head-up-tilt, heart rate variability, sympathetic activity, parasympathetic activity

$\mathrm{I}^{\mathrm{t}}$ is commonly perceived that a regular heartbeat is a sign of good cardiac health. However, sinus rhythm, the rhythm of healthy heart, or the successive cardiac cycle length is characterised by significant variability ${ }^{1}$. Therefore, normal heart rate is not characterised by clockwise regularity. In fact, preferably regular cardiac cycle length may signify disease condition ${ }^{2,3}$. Variation in successive cycle length is called the heart rate variability (HRV). The heart rate fluctuates with phase of respiration: cardio-acceleration during inspiration and cardio inhibition during expiration ${ }^{4}$. The relationship between heart rate (HR) and heart rate variability (HRV) are not simple but, both depend on autonomic nervous system; so they are not independent variables. The quantification of HRV is influenced by HR level ${ }^{5}$. So, heart rate and heart rate variability variables represent quite different characteristics of autonomic nervous activity ${ }^{6}$.
Measurement: Time domain and frequency domain analysis ${ }^{7}$.

Time domain analysis

In a continuous electrocardiograph (ECG) record, successive QRS complex (R peaks) detected and intervals between are called normal to normal (NN) intervals. 
Statistical methods: The most commonly used measure derived from interval differences include RMSSD (the square root of the mean squared differences of successive NN intervals), NN 50, the number of interval differences of successive $\mathrm{NN}$ intervals greater than 50 $\mathrm{ms}$, and pNN50 (percentage NN50 count). Geometrical methods: The geometrical method uses the sequence of RR intervals to construct a certain geometrical forms and extract the assessment of HRV from this. e.g. Lorenz plot or Poincare plot SD1, which represents the short term HRV and SD2, which represents long term $\mathrm{HRV}^{8}$.

Frequency domain (Power spectrum) analysis

In the frequency domain measure, power spectral densities of R-R intervals are plotted and different frequency components are identified. It includes the high frequency (HF) components $(0.15-0.40 \mathrm{~Hz})$ its power, percentage and normalized unit value that represents vagal modulation of HRV; and low frequency (LF) components (0.03-0.15 Hz) and its power, parentage and normalised unit value that represents sympathetic modulation ${ }^{9}$. LF/HF ratio represents sympathovagal balance ${ }^{7}$.

\section{Head up tilt}

Head up tilt is one of the experimental models of orthostatic test commonly used for autonomic test including HRV. On moving from supine to erect position there is large gravitational shift of the blood away from the chest to the distensible venous capacitance system below the diaphragm. So during head up tilt, a hydrostatic venous pooling in the extremities occurs owing to gravity ${ }^{10}$. In addition, with prolonged standing, the high capillary transmural pressure in dependant parts of the body causes filtrations of protein free fluid in to the interstitial spaces. It is estimated that this results in $15-20 \%(700 \mathrm{ml})$ decrease in the plasma volume in 10 minutes in healthy adult humans ${ }^{11}$. As a consequence of this, venous return to heart is reduced resulting in the rapid diminution of cardiac filling pressure and, thereby decrease in stroke volume. Despite decreased cardiac output, a fall in mean arterial pressure is prevented by a compensatory vasoconstriction of the resistance and capacitance vessels in the splanchnic, musculocutaneous, and renal vascular beds within a minute. Vasoconstriction of the systemic blood vessels is the key factor in the maintenance of arterial blood pressure in the upright posture. There is pronounced HR increase to maintain cardiac output ${ }^{11}$. These rapid short terms adjustment to orthostatic stress is mediated exclusively by the autonomic nervous system. During prolonged orthostatic stress, additional adjustments are mediated by the hormonal limb of the neuroendocrine system ${ }^{11}$. The static increase in skeletal muscle tone induced by the upright posture opposes the pooling of the blood in the limb veins even in the absence of movement of the subjects ${ }^{12}$. However, this mechanism does not operate in head up tilt. Failure of above discussed compensatory adjustments to orthostatic stress is thought to play a predominant role in the large number of patients with syncope. This forms the basis for the use of tilt testing in the evaluation of patients with syncope. There is a large body of literature on the mechanism involved in vasovagal syncope induced by tilt testing. Yet, many unanswered questions remain regarding the multiple potential caused and underlined physiologies. In the normal subject, passive head up tilt virtually always leads a reduction in vagal and increase in sympathetic modulation to heart rate.

Most of literature report tilts between angles of $45^{\circ}$ to $90^{\circ}$. However, tilt at $10^{\circ}$ which is analogous to usual day to day activity, lying down with a pillow or back rest for patients is rare in the available literature. Therefore, this study was aimed at exploring effect on graded head up tilt.

\section{Materials and methods}

This self-controlled experimental study was conducted in 30 consenting healthy adult men (18-35 years) in the Human Physiology Lab of Department of Physiology, BPKIHS. The subjects were selected using convenient sampling techniques, according to following inclusion and exclusion criteria. Inclusion criteria: I. subjects with low nicotine ${ }^{13}$ and alcohol dependence ${ }^{14}$ (i.e. with nicotine dependence score $\leq 4$ and alcohol disorder identification (AUDIT) $<8$. II. Mediation free subjects with the supine $\mathrm{BP}<140 / 90 \mathrm{mmHg}$ and the body mass index $(\mathrm{BMI}) \leq 25$. Exclusion criteria: subjects with past history of syncope and with the presence of diabetes mellitus, cardiovascular disorder, drug dependence and other diseases that is likely to affect autonomic function.

Recording procedure: The subjects were instructed not to take tea or coffee at least for 4 hours before test. Alcohol was forbidden 24 hours prior to test. The recording was done in morning hours between 8:00 to 12:00 hours after $15 \mathrm{~min}$ of supine rest. The resting ECG with spontaneous respiration at three positions first at supine followed by $10^{\circ}$ and $70^{\circ}$ were recorded for 5 minutes in the computer. The ECG signals for HRV were captured using Coulbourn Instrument and its software Windaq pro/pro+. From this software R-R intervals were obtained, which were manually checked and edited. Then from R-R intervals different parameters of time and frequency domain measure of HRV were calculated by using HRV analysis software $1.1^{15}$. 
Statistical analysis: Descriptive and inferential statistics of all the variables of the time domain and frequency domain measure of HRV were done along with age, BMI, respiratory rate, blood pressure. Multiple comparisons among the variables were analyzed by one way ANOVA and Bonferroni tests of multiple comparisons using software SPSS version 10.2.

\section{Results}

The mean age of the subjects was $25.37 \pm 3.89$ years and their BMI ranged from 18.11 to $24.72 \mathrm{~kg} / \mathrm{m}^{2}$ (mean= $20.77 \pm 2.1 \mathrm{~kg} / \mathrm{m}^{2}$ )

Effect of graded head up tilt on cardiopulmonary variables

No significant difference in respiratory rate and systolic blood pressure in response to $10^{\circ}$ or $70^{\circ}$ tilt were observed in the present study. The diastolic blood pressure was significantly increased in response to
70 degree tilt compared to 10 degree $(81.07 \pm 6.94$ vs. $75.87 \pm 8.10 \mathrm{mmHg}, \mathrm{p}<0.05)$ tilt and supine $(81.07 \pm 6.94$ vs. $74.13 \pm 7.3 \mathrm{mmHg}, \mathrm{p}<0.01)$. The difference in heart rate was not significant in response to 10 degree head up tilt. Whereas, in response to 70 degree tilt as compared to supine, it increased significantly $(88.51 \pm 12.84$ vs. $70.48 \pm 8.17 \mathrm{bpm}, \mathrm{p}<0.001)$, the increases in heart rate at $70^{\circ}$ was also significant compared to $10^{\circ}$ tilt $(88.51 \pm 12.84$ vs. $70.22 \pm 8.67$ bpm, $\mathrm{p}<0.001)$.

Effect of graded head up tilt on HRV

The $70^{\circ}$ tilt significantly decreased the following vagal $\mathrm{HRV}$ indicators compared to $10^{\circ}$ and supine: RMSSD, NN50, pNN50, SDNN. (Table 2)

The $70^{\circ}$ tilt significantly decreased HF power, HF unit compared to $10^{\circ}$ and supine where as the same $70^{\circ}$ tilt increase LF power \%, LF normalised unit, and LF: HF ratio compared to $10^{\circ}$ and supine. (Table 3 ).

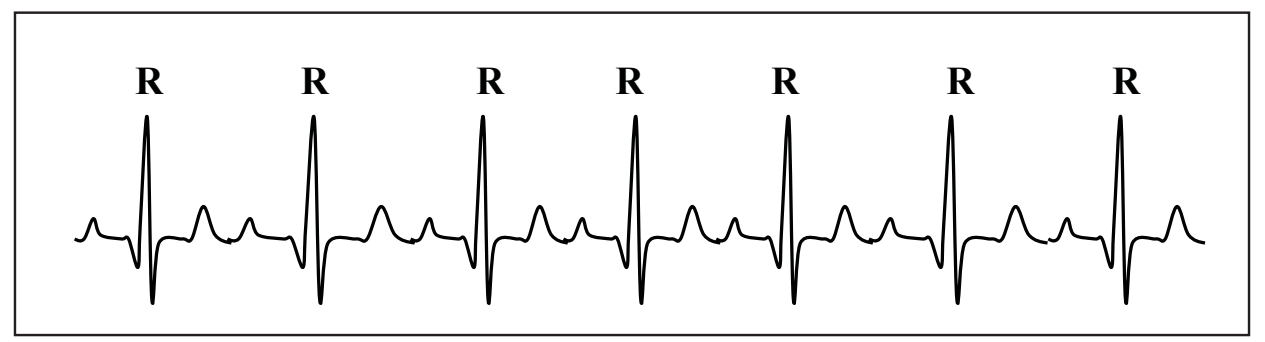

Fig 1: ECG graph showing R-R intervals

Table 1: Cardiopulmonary variables

\begin{tabular}{|l|c|c|c|c|}
\hline \multicolumn{1}{|c|}{ Variables } & Supine & At $\mathbf{1 0}^{\circ}$ tilt & At $\mathbf{7 0}^{\circ}$ tilt & P value \\
\hline SBP, $\mathrm{mmHg}$ & $118.60 \pm 8.98$ & $118.07 \pm 9.50$ & $121.20 \pm 9.46$ & $\mathrm{NS}$ \\
\hline DBP, $\mathrm{mmHg}$ & $74.13 \pm 7.30$ & $75.87 \pm 8.10$ & $81.07 \pm 6.94$ & $\begin{array}{c}\mathrm{p}<0.05\left(70^{\circ} \text { vs. } 10^{\circ}\right) \\
\mathrm{p}<0.01\left(70^{\circ} \text { vs. supine }\right)\end{array}$ \\
\hline Heart rate, bpm & $70.48 \pm 8.17$ & $70.22 \pm 8.67$ & $88.51 \pm 12.84$ & $\begin{array}{c}\text { NS }\left(10^{\circ} \text { vs. supine }\right) \\
\mathrm{p}<0.001\left(70^{\circ} \text { vs. Supine }\right) \\
\mathrm{p}<0.001\left(70^{\circ} \text { vs. } 10^{\circ}\right)\end{array}$ \\
\hline Respiratory rate, per minute & $18.03 \pm 2.04$ & $18.27 \pm 2.58$ & $19.20 \pm 3.17$ & $\mathrm{NS}$ \\
\hline
\end{tabular}

SBP: Systolic blood pressure, DBP: diastolic blood pressure, bpm: beats per minute. 
Table 2: Time domain variables

\begin{tabular}{|c|c|c|c|}
\hline Variables & \multicolumn{2}{|c|}{ Comparison among variables with mean \pm SD } & P value \\
\hline \multirow{2}{*}{ Mean RR (ms) } & \multirow{2}{*}{ Supine $=831.23 \pm 162.30$} & At $10^{\circ}$ tilt $=869.17 \pm 103.27$ & NS \\
\hline & & At $70^{\circ}$ tilt $=687.07 \pm 94.81$ & $\mathrm{p}<0.001$ \\
\hline \multirow{2}{*}{ SD of RR (ms) } & \multirow{2}{*}{ Supine $=38.13 \pm 10.89$} & At $10^{\circ}$ tilt $=38.07 \pm 11.29$ & NS \\
\hline & & At $70^{\circ}$ tilt $=31.13 \pm 8.12$ & $\mathrm{p}<0.05$ \\
\hline \multirow{2}{*}{ RMSSD (ms) } & \multirow{2}{*}{ Supine $=36.16 \pm 12.22$} & At $10^{\circ}$ tilt $=34.23 \pm 14.22$ & NS \\
\hline & & At $70^{\circ}$ tilt $=20.06 \pm 8.47$ & $\mathrm{p}<0.001$ \\
\hline \multirow{2}{*}{ NN50 count } & \multirow{2}{*}{ Supine $=55.27 \pm 44.10$} & At $10^{\circ}$ tilt $=45.07 \pm 44.44$ & NS \\
\hline & & At $70^{\circ}$ tilt $=13.03 \pm 20.58$ & $\mathrm{p}<0.001$ \\
\hline \multirow{2}{*}{ pNN50 } & \multirow{2}{*}{ Supine $=16.65 \pm 14.23$} & At $10^{\circ}$ tilt $=14.06 \pm 15.65$ & NS \\
\hline & & At $70^{\circ}$ tilt $=3.28 \pm 6.08$ & $\mathrm{p}<0.001$ \\
\hline \multirow{2}{*}{ SD1 } & \multirow[t]{2}{*}{ Supine $=25.93 \pm 8.72$} & At $10^{\circ}$ tilt $=24.55 \pm 10.14$ & NS \\
\hline & & At $70^{\circ}$ tilt $=14.73 \pm 6.14$ & $\mathrm{p}<0.001$ \\
\hline \multirow{2}{*}{ SD2 } & \multirow{2}{*}{ Supine $=56.40 \pm 18.23$} & At $10^{\circ}$ tilt $=57.33 \pm 18.34$ & NS \\
\hline & & At $70^{\circ}$ tilt $=49.18 \pm 13.24$ & NS \\
\hline
\end{tabular}

Mean RR: Mean of RR intervals, SD of RR: Standard deviation of RR intervals, RMSSD: The root mean square of differences of successive RR intervals, NN50: No. of RR intervals that differ by more than $50 \mathrm{~ms}$, pNN50: The percentage value of consecutive RR intervals that differ by more than $50 \mathrm{~ms}$.

Table 3: Frequency domain variables

\begin{tabular}{|c|c|c|c|}
\hline Variables & \multicolumn{2}{|c|}{ Comparison among variables with mean \pm SD } & P value \\
\hline \multirow{2}{*}{ VLF peak, Hz } & \multirow{2}{*}{ Supine $=0.023 \pm 0.008$} & At $10^{\circ}$ tilt $=0.02 \pm 0.07$ & NS \\
\hline & & At $70^{\circ}$ tilt $=0.023 \pm 0.006$ & NS \\
\hline \multirow{2}{*}{ VLF power, $\mathrm{ms}^{2}$} & \multirow{2}{*}{ Supine $=96.97 \pm 81.38$} & At $10^{\circ}$ tilt $=121.93 \pm 117.32$ & NS \\
\hline & & At $70^{\circ}$ tilt $=67.9 \pm 50.36$ & NS \\
\hline \multirow{2}{*}{ VLF power $\%$} & \multirow{2}{*}{ Supine $=18.88 \pm 7.87$} & At $10^{\circ}$ tilt $=23.76 \pm 10.59$ & NS \\
\hline & & At $70^{\circ}$ tilt $=21.25 \pm 11.13$ & NS \\
\hline \multirow{2}{*}{ LF peak, Hz } & \multirow{2}{*}{ Supine $=0.09 \pm 0.33$} & At $10^{\circ}$ tilt $0.083 \pm 0.03$ & NS \\
\hline & & At $70^{\circ}$ tilt $=0.082 \pm 0.15$ & NS \\
\hline \multirow{2}{*}{ LF power, $\mathrm{ms}^{2}$} & \multirow{2}{*}{ Supine $=216.87 \pm 150.98$} & At $10^{\circ}$ tilt $=218.17 \pm 155.85$ & NS \\
\hline & & At $70^{\circ}$ tilt $=197.20 \pm 143.76$ & NS \\
\hline \multirow{2}{*}{ LF power $\%$} & \multirow{2}{*}{ Supine $=41.61 \pm 14.29$} & At $10^{\circ}$ tilt $=40.73 \pm 11.58$ & NS \\
\hline & & At $70^{\circ}$ tilt $=59.52 \pm 14.50$ & $\mathrm{p}<0.001$ \\
\hline \multirow{2}{*}{ LF nu } & \multirow{2}{*}{ Supine $=52.32 \pm 19.89$} & At $10^{\circ}$ tilt $=54.52 \pm 16.34$ & NS \\
\hline & & At $70^{\circ}$ tilt $=75.72 \pm 14.76$ & $\mathrm{p}<0.001$ \\
\hline \multirow{2}{*}{ HF peak, Hz } & \multirow[t]{2}{*}{ Supine $=0.26 \pm 0.72$} & At $10^{\circ}$ tilt $=0.25 \pm 0.067$ & NS \\
\hline & & At $70^{\circ}$ tilt $=0.24 \pm 0.69$ & NS \\
\hline \multirow{2}{*}{ HF power, $\mathrm{ms}^{2}$} & \multirow{2}{*}{ Supine $=207.67 \pm 181.22$} & At $10^{\circ}$ tilt $=189.57 \pm 167.81$ & NS \\
\hline & & At $70^{\circ}$ tilt $=72.70 \pm 101.17$ & $\mathrm{p}<0.01$ \\
\hline \multirow[t]{2}{*}{ HF power $\%$} & \multirow[t]{2}{*}{ Supine $=39.57 \pm 18.54$} & At $10^{\circ}$ tilt $=35.49 \pm 15.75$ & NS \\
\hline & & At $70^{\circ}$ tilt $=19.31 \pm 13.25$ & $\mathrm{p}<0.001$ \\
\hline \multirow{2}{*}{ HF nu } & \multirow{2}{*}{ Supine $=47.67 \pm 19.89$} & At $10^{\circ}$ tilt $=45.48 \pm 16.34$ & 1.000 \\
\hline & & At $70^{\circ}$ tilt $=24.28 \pm 14.16$ & $\mathrm{p}<0.001$ \\
\hline \multirow{2}{*}{$\mathrm{LF} / \mathrm{HF}$} & \multirow{2}{*}{ Supine $=1.69 \pm 1.67$} & At $10^{\circ}$ tilt $=1.53 \pm 1.138$ & NS \\
\hline & & At $70^{\circ}$ tilt $=4.96 \pm 4.08$ & $\mathrm{p}<0.001$ \\
\hline
\end{tabular}

VLF: very low frequency, LF: low frequency, HF: high frequency, nu: normalized unit 


\section{Discussion}

Heart rate variability, which routinely used in the assessment of haemodynamics in the western countries is a tool established in 1980s for assessment of autonomic regulation of cardiac rhythm ${ }^{7}$. It can delineate sympathetic and parasympathetic contribution to heart rate regulation, thus making it very sensitive to diagnose autonomic neuropathy in its sub-clinical stage in diabetes mellitus. The HRV has special significance in risk stratification of post-myocardial infarction. It is an independent predictor of sudden cardiac death.

Head up tilt (orthostatic test) is the experimental procedure of passive standing resulting in the gravitational shift of the blood to lower extremities, which results in reduced venous return to the heart and, thereby decreasing stroke volume.

This study attempts to explore the HRV response to graded $10^{\circ}$ and $70^{\circ}$ tilts from supine position. The study showed no significant change in cardiovascular parameters at $10^{\circ}$ tilt of head up tilt compared to supine. So, cardiovascular response at supine and $10^{\circ}$ tilt is statistically similar. But, cardiovascular parameters changed in response to $70^{\circ}$ tilt compared to supine and $10^{\circ}$. It is also known from the literature that there is no change in systolic blood pressure in response to tilt ${ }^{36}$. This is consistent with our study that we did not find significant difference in systolic blood pressure in response to $10^{\circ}$ or $70^{\circ}$ of head up tilt. The heart rate in case of higher degree of tilt involves an early rise due to vagal withdrawal and more delayed increase over first two minutes caused by enhanced sympathetic activity. The heart rate increased at $70^{\circ}$ in our study.

\section{Effect of graded head up tilt in time domain measure of HRV}

There was corresponding decrease in HRV measure, believed to be vagal: SDNN, RMSSD, NN50, pNN50 and SD1. Among the time domain measure, mean $\mathrm{RR}$ interval was significantly decreased in response to $70^{\circ}$ tilt as compared to $10^{\circ}$ tilt or supine. Literature suggests non significant decrease in SDNN intervals with passive tilt ${ }^{15}$. However, in our study the SDNN interval decreased significantly in response to $70^{\circ}$ tilt as compared to $10^{\circ}$ tilt or supine. The difference was probable due to method applied; most of the tilt tables used was of foot supporting type of tilt table compared to table with only support on the centre not the foot, which we have used. So, no skeletal muscles were involved to support venous return in our ser up of passive standing and hence, the difference was much pronounced. The RMSSD is one of the most common parameters based on interval differences that correspond to short term HRV changes and are not dependant on day and night variations ${ }^{16}$. It was significantly decreased in response to $70^{\circ}$ of head up tilt as compared to $10^{\circ}$ tilt or supine. The NN50 count decreased significantly in response to $70^{\circ}$ tilt compared to $10^{\circ}$ or supine. Similarly, significant decrease in pNN50 was observed in response to $70^{\circ}$ of tilt compared to $10^{\circ}$ or supine. This pNN50 is one of the most common parameters that correspond to short term HRV changes. Among the geometrical methods, Poincare plot SD1, that represents the short term HRV was significantly decreased in response to $70^{\circ}$ tilt as compared to $10^{\circ}$ or supine, whereas the Poincare plot $\mathrm{SD} 2$, that represents the long term HRV, remained unchanged among the different degree of tilt.

Effect of graded head up tilt on frequency domain measure of HRV

It is known that in normal subjects, head up tilt leads to decrease in high frequency components of HRV that that represents the vagal modulation to heart ${ }^{15,17}$. At the same time, it leads to increase in low frequency components ${ }^{18}$ that represent the sympathetic modulation to heart. So, head up tilt leads to vagal withdrawal ${ }^{18}$. In our study, HF peak did not change in response to $10^{\circ}$ or $70^{\circ}$ tilt from supine but the HF power, its percentage value and the $\mathrm{HF}$ normalized unit decreased in response to $70^{\circ}$ tilt as compared to $10^{\circ}$ tilt and supine. However, there was no significant difference in LF peak, and its power in response to tilt to $70^{\circ}$, where as the LF power percentage increased in response to $70^{\circ}$ as compared to $10^{\circ}$ and supine. In the same way, the LF normalized unit also increased in response to $70^{\circ}$ tilt as compared to $10^{\circ}$ and supine. LF to HF ratio has been considered as sympathovagal balance, which changes in response to head up tilt angle above 30 degree ${ }^{19}$. The LF: HR ratio increased significantly at $70^{\circ}$ compared to $10^{\circ}$ or supine. Very low frequency components remained statistically similar at supine, $10^{\circ}$ and $70^{\circ}$. It was interesting to note that changes in HRV in response to tilt occurred without change in respiratory frequency.

\section{Strength and limitation of the study}

In cardiovascular evaluation, different degrees of tilt are applied. However, tit at $10^{\circ}$ has rarely been found in the available literature. Therefore, a $10^{\circ}$ tilt is one of the frequent positions used in everyday practice. Hence, it was worth studying HRV changes in this position. But it was found to be similar to supine posture in terms of HRV.

This study has some limitations, the major of which is the limitation of time, due to which this study could not be carried out on a large sample size, besides this study was carried out only on males. So result of the study cannot be generalised on both sexes.

Conclusion

At $70^{\circ}$ of head up tilt, HRV measures reflecting vagal contribution to cardiac-cycle length decreased with 
reciprocal increase in sympathetic activity compared to $10^{\circ}$ tilt or supine leading to increase in sympathetic predominance. $\mathrm{LF}$ to $\mathrm{HF}$ ratio, which reflects the sympathovagal balance, was found to be increased at $70^{\circ}$ tilt. So with tilt of higher angle there is increase in sympathetic activity and decrease in parasympathetic activity. The $10^{\circ}$ tilt, which is almost equivalent to lying down with a pillow, did not change HRV from supine. So, $10^{\circ}$ tilt is physiologically similar to supine position. It can also be said that passive inclination to $10^{\circ}$ tilt does not cause significant haemodynamics change to produce appreciable changes in blood pressure and HRV.

\section{Acknowledgements}

Authors like to thank all the family members of Department of Physiology, BPKIHS for providing opportunity to carry out this research work. Authors are deeply indebted to all the volunteers who participated in the study.

\section{References}

1. Kleiger RE, Stein PK, Bosner MS, Rottman JN. Time domain measurements of heart rate variability. Cardiology Clinics. 1992;10(3):48798.

2. Kleiger RE, Miller JP, Bigger JT, Moss AJ. Decreased heart rate variability and its association with increased mortality after acute myocardial infarction. Am J Cardiol. 1987;59(4):256-62.

3. Huikuri HV, Mäkikallio TH, Airaksinen KE, Airaksinin KE, Seppanen T, Puukka P, Raiha IJ, et al. Power-law relationship of heart rate variability as a predictor of mortality in the elderly. Circulation. 1998;97(20):2031-6.

4. MacArthur network on SES and Health [homepage on the Internet]. Kawachi I: Heart Rate Variability [updated dec 2001; cited may 2006]. Available from: http://www.macses.ucsf. edu/Research/Allostatic/notebook/heart.rate. html

5. Coumel P, Maison-Blanche P, Catuli D.In Malik M, Camm AJ. Heart Rate Variability. Eds. Heart rate and heart rate variability. New York: Futura Publishing Company;1995. P. 207-8.

6. Hirayanagi K, Iwasaki K, Sasaki T, Kinugasa H, Miyamoto A, Yajima K. Sensitivity analyses of heart rate variability variables by an incremental, passive head-up tilt. Uchu Koku Kankyo Igaku. 1999; 36(2):67-74.

7. Task force of European Society of Cardiology and The North American Society of Pacing and Electro physiology. Heart rate variability. European Heart Journal. 1996;17:354-81.
8. Malik M. Heart Rate Variability. In Malik M, Camm AJ, eds. Geometrical Methods for Heart Rate variability. New York: Futura Publishing Company; 1995. P.47-8.

9. Cerutti C, Bianchi AM, Mainardi LT. Spectral analysis of Heart rate variability signal. In Malik M, Camm AJ, editors. Heart rate variability. New York: Futura Publishing Company;1995.p. 64-74.

10. Kitamura K, Takata S, Futamata H, Teragami T, Hashimoto T. Effects of head-up tilting on vagal nerve activity in man. Rinsho Byori. 1997;45(8):771-7.

11. Smit AAJ, Halliwill JR, Low Pa, Wieling W, et al. Pathophysiological basis of orthostatic hypotension in autonomic failure. J Physiol. 1999;519:1-10.

12. Dandona P, James IM, Newburry PA, Woollard HL, Beckett AG, et al. Cerebral blood flow in diabetes mellitus: evidence of abnormal cerebral vascular reactivity. Br Med J. 1978;2:325-6.

13. Heatherton TF, Kozlowski LT, Frecker RC, Fagerstrom KO. The Fagerstrom Test for Nicotine Dependence: A revision of the Fagerstrom Tolerance Questionnaire. British Journal of Addictions. 1991;86:1119-27.

14. Baboor TF, Higgins-Biddle JC, Saunders JB, Monteiro MG. The Alcohol Use Disorder Identification Test: Guidelines for Use in Primary Care. 2nd Edition. Geneva: World Health Organisation; 2001.

15. Vybiral T, Bryg RJ, Maddens ME, Boden WE. Effect of passive tilt on sympathetic and parasympathetic components of heart rate variability in normal subjects. Am J Cardiol. 1989; 63(15):1117-20.

16. Sztajzel F. Heart rate variability: a non-invasive electrocardiographic method to measure the autonomic nervous system. Swiss med wkly. 2004;134:512-22.

17. Arai $H$, Sato H, Yamamoto $M$, Uchida $M$, Nakamachi T, Kaneko T et al. changes in the fractal component of spectral analysis of heart rate variability and systolic blood pressure variability during head up tilt test. J Cardiol. 1999;34(4):211-7.

18. Saul JP, Bernardi L. Heart rate variability. In Malik M, Camm AJ, editors. Heart rate variability after cardiac transplantation. New York : Futura Publishing Company;1995. p.488-89.

19. Yokoi Y, Aoki K. Relationship between blood pressure and heart-rate variability during graded head-up tilt. Acta Physiol Scand. 1999;165(2):155-61. 